\title{
Práticas de ensino e formação docente: notas sobre a experiência da Licenciatura em Filosofia da UFABC
}

Teaching practices and teacher training:notes on the experience of UFABC's Philosophy course

\author{
Marinê de Souza Pereira* \\ Universidade Federal do $A B C$ \\ Patricia Del Nero Velasco** \\ Universidade Federal do $A B C$
}

Resumo O presente artigo tem como objetivo refletir sobre a concepção de prática de ensino como experiência de formação docente. Para tanto, inicia com uma série de questionamentos sobre a Filosofia como disciplina escolar; na sequência, aborda a ideia de prática como componente curricular, discutindo algumas de suas possíveis interpretações; por fim, apresenta a proposta do Curso de Licenciatura em Filosofia da Universidade Federal do ABC, analisando em que medida os cinco módulos de práticas de ensino do referido curso pretendem se constituir em espaços de experiência formativa de professores, conciliando as reflexões sobre o Ensino de Filosofia com as problematizações que caracterizam o filosofar.

PALAVRAS-Chave: Prática de Ensino, Formação Docente, Licenciatura em Filosofia.

Abstract This article aims to reflect on the conception of teaching practice as an experience of teacher training. It begins with a series of questions about the philosophy as a school subject; discusses the idea of practice as a curriculum component, questioning some possible interpretations; finally, presents the proposal of UFABC's Philosophy course, analyzing how the five modules of practical teaching constitute in spaces of formative experience of teachers.

KEYWORDS: Teaching Practice, Teacher Training, Philosophy Course. 


\section{Sobre a Filosofia como disciplina escolar: alguns questionamentos}

A presença da Filosofia como disciplina obrigatória na matriz curricular do Ensino Médio brasileiro coloca em cena a necessidade de discussão de determinadas questões. A primeira delas diz respeito ao desafio de transformar a Filosofia em disciplina escolar. A princípio, o espaço da sala de aula como o de sistematização de saberes para transmissão ${ }^{1}$ contraria a natureza inquieta e problematizadora da Filosofia. Pergunta-se: como fazer da sala de aula um espaço de abertura para o pensamento propriamente filosófico?

Um segundo questionamento se refere à constituição de um currículo. Dado que a obrigatoriedade da Filosofia como disciplina da Educação Básica data de 2008, pode-se afirmar que não há uma tradição curricular, mas, contrariamente, há inúmeras possibilidades para a escolha de conteúdos filosóficos. ${ }^{2}$ Nesse sentido, como propor currículos que não engessem a prática docente?

Intimamente relacionada ao tema do currículo, a discussão sobre os materiais didáticos figura como terceira e necessária problematização acerca da Filosofia como disciplina escolar. Para o ano letivo de 2015, foram selecionadas cinco obras no âmbito do Programa Nacional do Livro Didático. ${ }^{3}$ Sobre estas, interroga-se: atendem, de fato, aos alunos e professores de Ensino Médio da rede pública de todo o Brasil? Ainda que a resposta seja afirmativa, que outros materiais poderiam ser criados para viabilizar um ensino filosófico da Filosofia?

Além disso: como promover um aprendizado efetivamente significativo para o aluno da etapa terminal da Educação Básica? Esta é a quarta pergunta que a presença da Filosofia na escola impõe. Se tomarmos como próprio da Filosofia o movimento do pensamento, teremos que responder: como ensinar este movimento? Se entendermos que o ensino filosófico deve levar em conta a experiência de ressignificação de problemas em sala de aula, como precisaria ser lida a tradição filosófica para fazer dela objeto de reflexão da própria realidade?

Embora pudéssemos listar ainda inúmeras outras questões, fecharemos esta parte inicial do texto com um último e prioritário tema, a saber, a formação docente, cerne do presente trabalho. Um diagnóstico usual da área de Ensino atesta que os cursos de Licenciatura não oferecem uma formação sólida e condizente com o cenário educacional vigente; logo, muitos licenciandos vão se tornando professores apenas na sua prática docente. Fica, então, a questão: como formar bons professores de Filosofia para atuarem no nível médio de ensino?

A problematização da formação docente, a nosso ver, figura como imprescindível aos demais questionamentos enunciados, quais sejam, os que versam sobre o desafio de transformar a Filosofia em disciplina escolar, a constituição de um currículo e de materiais didáticos e a promoção de um aprendizado efetivamente significativo para os estudantes do Ensino Médio. Dessa maneira, embora o presente trabalho não pretenda responder a estes questionamentos iniciais, considera que, ao enunciá-los, sinaliza e enaltece o tema-cerne que pretende abordar: a formação do professor. De 
modo mais específico, neste artigo procurar-se-á discutir as práticas de ensino como experiências de formação docente em Filosofia, tomando como base para as reflexões a proposta do Curso de Licenciatura da Universidade Federal do ABC.

\section{Concepção de prática na experiência de formação docente em Filosofia}

A Universidade Federal do ABC (UFABC) é uma instituição interdisciplinar e todos os cursos de formação específica contêm, em sua estrutura, uma matriz curricular com essa natureza. No caso do curso de Licenciatura em Filosofia, a matriz interdisciplinar diz respeito às disciplinas comuns ao Bacharelado em Ciências e Humanidades $(\mathrm{BC} \& \mathrm{H})$. O estudante ingressa no $\mathrm{BC} \& \mathrm{H}$ e, antes mesmo de integralizar os créditos deste bacharelado, pode optar por diferentes cursos: Ciências Econômicas, Planejamento Territorial, Políticas Públicas e Relações Internacionais, além do Bacharelado e da Licenciatura em Filosofia.

O aluno que escolhe cursar a Licenciatura em Filosofia, necessariamente, cursará também as disciplinas obrigatórias do $\mathrm{BC} \& \mathrm{H}$, quais sejam: Bases Computacionais da Ciência; Bases Epistemológicas da Ciência Moderna; Bases Matemáticas; Ciência, Tecnologia e Sociedade; Conhecimento e Ética; Desenvolvimento e Sustentabilidade; Energia: origens, conversão e uso; Estado e Relações de Poder; Estrutura da Matéria; Estrutura e Dinâmica Social; Identidade e Cultura; Introdução à Probabilidade e à Estatística; Nascimento e Desenvolvimento da Ciência Moderna; Origem da Vida e Diversidade dos Seres Vivos; Pensamento Crítico; Pensamento Econômico; Problemas Metodológicos das Ciências Sociais; Projeto Dirigido; Temas e Problemas em Filosofia; Teorias da Justiça; Território e Sociedade. ${ }^{4}$

Afora o rol de disciplinas comuns ao $\mathrm{BC} \& \mathrm{H}$, há outras que são comuns ao Bacharelado em Filosofia: Estética, Ética, Filosofia da Linguagem, Filosofia no Brasil e na América Latina, Filosofia Política, Lógica Básica, Problemas Metafísicos: Perspectivas Modernas, Teoria do Conhecimento: Empirismo versus Racionalismo, História da Filosofia Antiga: Platão e o platonismo, História da Filosofia Antiga: Aristóteles e o aristotelismo, História da Filosofia Medieval: Patrística e Escolástica, História da Filosofia Moderna: perspectivas racionalistas, História da Filosofia Moderna: o Iluminismo e seus desdobramentos, História da Filosofia Contemporânea: o Século XIX, História da Filosofia Contemporânea: o Século XX.

Ademais, há disciplinas pedagógicas também ministradas em outros cursos de licenciatura da UFABC (Ciências Biológicas, Matemática, Física e Química): Desenvolvimento e Aprendizagem, Didática, LIBRAS e Políticas Educacionais.

Por fim, compõe a matriz curricular da Licenciatura em Filosofia, além dos estágios supervisionados, um leque de disciplinas específicas do referido curso, a saber: Filosofia da Educação, Filosofia do Ensino de Filosofia e cinco módulos de Prática de Ensino de Filosofia. Sobre este conjunto de disciplinas específicas da Licenciatura em Filosofia é que gostaríamos de refletir nas linhas que seguem. ${ }^{5}$ Ou seja, pretendemos tratar, aqui, da concepção de prática na experiência formativa do referido curso, tanto 
no que diz respeito ao processo de criação do mesmo quanto no que se refere à ação educadora e criativa que nele tem tido lugar.

Criado dentro da perspectiva de pensar o Ensino de Filosofia como problema e objeto de pesquisa da própria Filosofia, o curso da UFABC parte "do suposto de que ensinar Filosofia e transmiti-la exige, de imediato, uma inserção na própria Filosofia, cuja definição já seria em si mesma um problema filosófico" (VELASCO, 2014, p. 20). Procura, pois, formar professores que reconhecem os pressupostos filosóficos e pedagógicos do ensino da Filosofia e são capazes de refletir sobre a própria prática docente, "tomando o ensino-aprendizagem como momento de redescoberta da própria atividade filosófica” (VELASCO, 2014, p. 21).

Assim, no Projeto Pedagógico do curso lemos que:

O Curso de Licenciatura em Filosofia da UFABC [...] propõe uma formação do futuro docente que concilia as reflexões sobre o ensino de Filosofia com as problematizações que caracterizam o filosofar.

$[\ldots]$

Deste modo, entende que [...] o diálogo possível entre Filosofia e sala de aula precisa ser construído a partir de fundamentos teóricos sobre a identidade da Filosofia e do filosofar, a função e a finalidade da disciplina em questão, o que ensinar e como fazê-lo, as relações entre a Filosofia e sua história e, igualmente, sobre as relações entre Filosofia e Educação.

Por se constituir a partir da discussão dos fundamentos teóricos supramencionados, o Curso de Licenciatura em Filosofia da UFABC tem uma identidade própria: trata-se de um projeto específico que embora dialogue com o Bacharelado em Filosofia, não se confunde com este. (UNIVERSIDADE FEDERAL DO ABC, 2010, p. 9).

Tal compreensão sobre o Ensino de Filosofia traz elementos importantes para o processo atual de reflexão sobre o tema, principalmente se levarmos em conta que até pouco tempo os cursos de formação de professores se faziam pelo que ficou conhecido como modelo "3+1", numa visão "aplicacionista" do conhecimento, de acordo com a qual o aluno passava certo número de anos de sua formação assistindo aulas baseadas em conteúdos teóricos ou em conhecimentos proposicionais que, depois, seriam "aplicados" nos estágios, considerados como momento da prática - o que significava uma desvinculação entre ambos os momentos, o teórico e o prático. Modelo que teve seu papel na desvalorização da prática docente, considerada algo menos importante na tradição universitária brasileira, algo como um complemento prático do saber adquiri$\mathrm{do}^{6}$ - pensamento que ainda vigora em muitos cursos universitários.

Sabemos que a discussão sobre os problemas presentes nesse modelo culmina, de certa maneira, no processo de reforma na formação de professores, de modo que os documentos que originam tal processo passam a tratar a "prática" como atividade distinta do estágio supervisionado, no sentido de não se confundir com ele, ampliando o campo de compreensão da mesma, que passa a ser definida como "componente curricular". Um passo basilar para a reforma é a distinção das carreiras, tal como explicitado no Parecer CNE/CP n. 9/2001, fundamental para a compreensão das mudanças que 
ocorreram e começaram a vigorar a partir de então - se não de fato, ao menos de direito, já que a legislação por si só não garante a efetiva transformação da, por assim dizer, mentalidade tradicionalmente dominante. Nele, lemos que:

O processo de elaboração das propostas de diretrizes curriculares para a graduação, conduzido pela $\mathrm{SESu}$, consolidou a direção da formação para três categorias de carreiras: Bacharelado Acadêmico; Bacharelado profissionalizante e Licenciatura. Dessa forma, a Licenciatura ganhou, como determina a nova legislação, terminalidade e integralidade própria em relação ao Bacharelado, constituindo-se em um projeto específico. Isso exige a definição de currículos próprios da Licenciatura que não se confundam com o Bacharelado ou com a antiga formação de professores que ficou caracterizada como modelo 3+1. (BRASIL, 2001, p. 6).

E ainda que:

Uma concepção de prática mais como componente curricular implica vê-la como uma dimensão do conhecimento que tanto está presente nos cursos de formação, nos momentos em que se trabalha na reflexão sobre a atividade profissional, como durante o estágio, nos momentos em que se exercita a atividade profissional. (BRASIL, 2001, p. 23).

Assim, por mais que o estágio seja um momento prático, "em que se exercita a atividade profissional", o que o Parecer CNE/CP n. 9/2001 afirma, de modo explícito é que "A ideia a ser superada, enfim, é a de que o estágio é o espaço reservado à prática, enquanto na sala de aula se dá conta da teoria” (BRASIL, 2001, p. 23).

A essa concepção de "prática como componente curricular", que parece pretender uma articulação ou integração entre os "momentos em que se trabalha a reflexão sobre a atividade profissional" e aqueles "em que se exercita" tal atividade, diferentes interpretações podem se seguir. Uma delas poderia ser a de considerar que a dimensão prática deveria ser diluída ao longo do curso, nas disciplinas de caráter propositivo, que passariam a ter que responder pela formação docente também. Outra poderia ser a de considerar que bastaria criar uma ou outra disciplina "prática", com a finalidade de contemplar a nova legislação. Este último caso seria um desdobramento "natural" da tradição universitária supramencionada, para a qual deveria permanecer a separação entre as disciplinas propriamente filosóficas e as pedagógicas, sendo um bom professor alguém teoricamente bem formado - e basta. Concepção problemática, porque os cursos de Licenciatura em Filosofia, que são nela compreendidos, "não assumem a formação de professores como problema (e responsabilidade) da própria Filosofia, colocando nas escolas docentes que não têm familiaridade com a investigação científica, não examinam os pressupostos filosóficos da sua práxis e, portanto, não problematizam seu próprio ofício de dar aula" (VELASCO, 2014, p. 12).

Quanto à outra interpretação que mencionamos, há que pensar nos problemas que também adviriam dela. $\mathrm{O}$ primeiro deles seria a possível perda de profundidade dos conteúdos que a formação requer, independentemente do título em questão, de bacharel ou de licenciado. Nesse sentido, concordamos, sim, que para um 
bom professor é preciso uma boa formação teórica - apenas não concordamos que isso seja suficiente ou que a dimensão didático-pedagógica seja dispensável ou coisa que o valha. E mais. Fazer isso seria separar o ensino da pesquisa. Seria inverter a lógica, passando o "peso" da teoria para a prática, ou do Bacharelado para a Licenciatura, ou seja, seria manter a separação que se pensava superar diluindo a dimensão prática nas disciplinas propositivas. Entendemos que dar à Licenciatura "terminalidade e integralidade própria em relação ao Bacharelado, constituindo-se em um projeto específico" não significa separar ensino de pesquisa, teoria de prática ou incorrer em qualquer outra dicotomia que a velha tradição forjou no que tange à formação de professores. Outro problema estaria no risco de reprodução das práticas docentes, que poderiam ser tomadas como modelos a serem copiados, acarretando uma possível perda de autonomia do estudante em sua criação de propostas e materiais didáticos.

O Curso de Licenciatura em Filosofia da UFABC, ao propor uma formação que concilia as reflexões sobre o Ensino de Filosofia com as problematizações que caracterizam o filosofar, tem uma identidade própria, não se confundindo com o Bacharelado em Filosofia, mas estabelecendo com ele um profícuo diálogo. Muitas das suas disciplinas são comuns, criando nos alunos uma relação que beneficia ambos os cursos. Nas que são próprias à Licenciatura, acima mencionadas, o Ensino de Filosofia é tomado como problema filosófico, articulando internamente a prática docente com os conteúdos filosóficos. Cabe, agora, uma exposição de tais disciplinas, iniciando por aquela que discute diretamente o Ensino de Filosofia entre a questão pedagógica e a problemática filosófica, atentando para os pressupostos filosóficos deste ensino, a saber: Filosofia do Ensino de Filosofia.

Adota-se como referência bibliográfica básica da disciplina supracitada a obra de Cerletti, intitulada "O ensino de filosofia como problema filosófico" (2009). Abordam-se, pois, a intrínseca relação entre o "que" e o "como" se ensina; o ensino como uma forma de intervenção filosófica; a intencionalidade da pergunta filosófica (que a distingue dos questionamentos de outras naturezas); as dimensões de repetição (das informações históricas, das fontes filosóficas etc.) e de criação (as apropriações, a recriação dos problemas e das respostas etc.) do ensino-aprendizagem da filosofia; o valor formativo da filosofia e o próprio questionamento acerca da noção de "utilidade filosófica"; a formação como auto formação; as relações entre Filosofia, instituições educativas e Estado; a aula de Filosofia como momento de problematização compartilhada.

Ainda no escopo da disciplina Filosofia do Ensino de Filosofia, os alunos são convidados a construir e problematizar suas próprias concepções de Filosofia, ensaiando, igualmente, o que/como seria uma prática docente condizente com a imagem de Filosofia defendida: que tipo de conteúdos, metodologias, avaliações, materiais didáticos e habilidades cognitivas seriam priorizados?

O ensaio sobre o que e como ensinar, sob o registro filosófico, é também realizado nas disciplinas de Prática de Ensino, tema da seção procedente. 


\section{As práticas de ensino na licenciatura em Filosofia da UFABC}

Como supramencionado, cinco módulos de Prática de Ensino de Filosofia compõem o curso de Licenciatura em Filosofia da UFABC. No primeiro deles, buscase problematizar as possíveis justificativas para o ensino da Filosofia e o papel formativo desta no processo educativo. Discute-se em que medida "O ensino da filosofia não se contenta em jogar um papel no conjunto da função ensinante, mas que se confunde com essa função. [...] Sem ele os alunos ficam privados do que transforma a instrução em educação" (TASSIN, 1986, p. 147-149).

Sobre o caráter imprescindível do exercício filosófico para uma educação efetivamente formativa, escreve Severino (2005, p. 187-189):

É preciso recorrer à modalidade do conhecimento filosófico que é onde desenvolvemos nossa visão mais abrangente do sentido das coisas e da vida, que nos permite buscar, com a devida distância crítica, a significação de nossa existência, e o lugar de cada coisa nela. É o que comumente expressamos ao nos referir ao "pensar", ao refletir, ao argumentar, ao demonstrar, usando dos recursos naturais, comuns, da nossa subjetividade.

$[\ldots]$

Assim, se os conhecimentos científicos nos ajudam a entender as coisas, são os conhecimentos filosóficos que nos ajudam a compreendê-las, ou seja, a situá-las no conjunto de sentidos que norteiam a existência humana, a atribuir-lhes um sentido articulado numa rede maior de sentidos dessa existência, em sua complexa condição de unidade e de totalidade. (SEVERINO, 2005, p. 187-189).

Para o autor, a formação é um processo de aperfeiçoamento dos jovens como seres humanos. Impede-se que as ações humanas se tornem meramente instintivas ou mecânicas por meio do desenvolvimento da subjetividade em relação à inteligência e às consciências epistêmicas, estéticas, sociais e éticas: ao atribuir sentido às coisas, por meio da subjetividade, o homem atinge sua condição verdadeiramente humana. "E, para Severino, essa educação [...] não pode ocorrer sem a prática da filosofia, uma vez que é no conhecimento filosófico que se enxerga de forma global o sentido da existência humana. As significações sempre revistas, renovadas, mas sempre necessárias"(GOMES; VELASCO, 2009, p. 398).

Ainda a respeito do papel formativo da Filosofia, reflete-se, também, na disciplina de Prática de Ensino de Filosofia I sobre as funções filosóficas de fundamentação metodológica, de articulação intradisciplinar e de problematização das próprias relações de conhecimento.

A Filosofia tem uma função de articulação cultural e, ao desempenhá-la, realiza também aarticulação do indivíduo enquanto personagem social, se entendermosque o autêntico processo de socialização requer a consciência e o reconhecimentoda identidade social e uma compreensão crítica da relaçãohomem-mundo. No contexto curricular, a Filosofia mantém com as demais disciplinas um contato que deve traduzir-se concretamente numa aproximação do caráter geral 
da experiência de conhecimento. Isto é feito, de um lado, pensando as questões atinentes à fundamentação metodológica e, de outro, pela remissão às origens históricas da experiência teórica. Neste último sentido, a Filosofia presentifica a tradição esclarecendo o significado do progresso do conhecimento e das relações entre civilização e progresso técnico, para além da perspectiva sociológica do progresso de hominização. A fundamentação metodológica cumpre a função da articulação intradisciplinar[...], auxiliando o indivíduo a reconhecer-se na experiência do conhecer, isto é, despertando-o para a problemática da relação cognitiva. A presentificação da tradição tem a função de mostrar que o domínio racional é a um tempo dinâmico e permanente e que o conhecimento não é episódico e descontínuo, assim como a ação não é a justaposição de respostas instantâneas às solicitações da práxis. (SILVA, 1992, p. 163-164).

Os papéis de fundamentação metodológica (dada a sua natureza crítica) e reflexão sobre o processo de conhecimento (seu caráter histórico, a problematização da noção de progresso e de conhecimento verdadeiro etc.) aproximam a Filosofia das demais disciplinas, articulando-as. Se de um lado não se pode dizer que a Filosofia está no currículo como assessora metodológica das outras áreas do conhecimento, por outro, "seria grave infidelidade ao espírito filosófico entender que a Filosofia virá se agregar ao currículo apenas para tornar-se mais uma parte de um todo desconexo" (SILVA, 1992, p. 163). Dada a sua natureza, a Filosofia procura cumprir o papel de compreensão crítica das relações entre o indivíduo e o mundo, bem como de conscientização deste indivíduo como personagem social. Nesse viés, não se deve considerar a Filosofia como somente mais uma disciplina.

São igualmente exploradas outras possibilidades de justificativa para a Filosofia na escola: o desenvolvimento das capacidades de leitura, análise e abstração; o aperfeiçoamento das ferramentas conceituais de argumentação; a abertura para a interrogação e clarificação conceitual; a reflexão racional; a crítica sobre as condições de possibilidade do pensamento; a indagação sobre as questões de fundo: ${ }^{7}$ o que é o conhecimento? O ser? A realidade? O belo? O mundo? O justo? A verdade? O que é ser gente?...

Após a discussão sobre o valor formativo da Filosofia e as justificativas para seu ensino, na disciplina de Prática de Ensino de Filosofia II a temática central consiste nos documentos legais que norteiam o ensino em questão: os Parâmetros Curriculares Nacionais para o Ensino Médio (2000a; 2000b), as Orientações Educacionais Complementares aos Parâmetros Curriculares Nacionais(2002) e as Orientações Curriculares para o Ensino Médio (2006). Procura-se estudar os referidos documentos a partir da análise do sentido público da Educação. Tem-se como base para as reflexões o texto "A crise na educação", de Arendt (2006), no qual a autora critica os projetos educacionais progressistas, acusando-os de politizarem de modo excessivo a educação, infantilizando-a.

[...] Esse tema é central para uma crítica dos projetos contemporâneos de politização da educação, tal como recentemente proposto pelos Parâmetros Curriculares Nacionais, os quais, ao pretenderem politizar todas as dimensões do programa educacional, acabam, na 
verdade, por despolitizar a própria linguagem política: quando todas as dimensões da vida e da educação estão submetidas à ideia de cidadania, é o próprio exercício político ativo da cidadania que perdeu seu sentido e quase já não é mais exercitado. (CESAR; DUARTE, 2010, p. 828).

Além dos Parâmetros Curriculares Nacionais, as Orientações Curriculares para o Ensino Médio (2006) reforçam o esvaziamento da noção que subjaz ao ensino de Filosofia, a partir da legislação vigente: a ideia de cidadania. "Tendo em conta a necessidade de se esboçar alguma correlação entre conhecimentos de Filosofia e uma concepção de cidadania presente na legislação vigente" (BRASIL, 2006, p. 24), esse documento procura furtar-se àquilo que ele mesmo afirma criticável, a saber, "tentar justificar a Filosofia apenas por sua contribuição como um instrumental para a cidadania” (BRASIL, 2006, p. 25). Mas, nessa tentativa, acaba por manter a submissão da Filosofia em relação à concepção de cidadania presente na legislação vigente, mesmo tentando alargá-la ou desdobrando suas possibilidades de compreensão, uma vez que, ao final, "A pergunta que se coloca é: qual a contribuição específica da Filosofia em relação ao exercício da cidadania para essa etapa da formação?”(BRASIL, 2006, p. 26). Discutir tal questão significa refletir, também, sobre a concepção de Filosofia presente na legislação brasileira.

Possíveis metodologias para o ensino da Filosofia são o cerne da disciplina de Prática de Ensino de Filosofia III. Nesta, investigam-se as aproximações e divergências entre as propostas metodológicas do argentino Obiols (2002), do italiano $\mathrm{Ru}-$ ffaldi (2003) e do brasileiro Gallo (2012). Analisam-se, também, as possíveis relações entre História da Filosofia e Ensino, tendo como referência o clássico texto "História da Filosofia: centro ou referencial?", de Leopoldo e Silva (1987). Por fim, os estudantes ministram pequenas aulas ensaiando as metodologias estudadas no decorrer do curso.

Obiols (2002) ampara sua proposta na ideia de que a aprendizagem filosófica é inseparável de um conteúdo (as produções filosóficas) e de uma forma (a atitude do filosofar); defende, igualmente, que para uma aprendizagem significativa devem-se oferecer atividades de construção de significados e atribuição de sentidos aos conteúdos, sendo estes, conceitos, procedimentos e atitudes.Em vista disso, estabelece que o processo de ensino filosófico deva ser composto das seguintes estratégias: um início concreto, em que se motiva o estudante e se colocam os problemas; um desenvolvimento abstrato, no qual se discute o problema (conceituando, argumentando, comparando, etc.) a partir da análise de textos filosóficos, recorrendo-se à história da filosofia; e um encerramento novamente concreto, construído da síntese, aplicação e avaliação de todo o processo.

Ruffaldi (2003), por sua vez, a partir das tendências da didática da Filosofia na Itália, sugere que a sala de aula seja um laboratório, "organizada como lugar do com-filosofar" (RUFFALDI, 2003, p. 148) e da comunidade de pesquisa: o trabalho com a Filosofia, nessa proposta, não pode prescindir dos exercícios com temas, problemas, conceitos e argumentos, nem da centralidade dos textos filosóficos - a fim de "apropriar-se das ferramentas do pensar filosófico em seus diferentes procedimentos argumentativos" (RUFFALDI, 2003, p. 140). 
Tendo como fundamento teórico a crítica de Rancière (2002) à sociedade pedagogizada e as ideias de criação conceitual e "fazer com" (em detrimento do "fazer como") de Deleuze (2003; 2006), Gallo (2013) apresenta a proposta de aula de Filosofia como oficina de conceitos. Nesta, o ensino é pensado como experiência com conceitos (e com os problemas que os suscitaram).

Embora partam de diferentes perspectivas teóricas, as metodologias discutidas no curso guardam elementos comuns: o ensino filosófico da Filosofia não se sustenta sem o filosofar e, como tal, constitui-se a partir de determinados elementos: problemas, conceitos, argumentação e investigação textual (revisitando a História da Filosofia). O modo como estes elementos se entrelaçam, o enfoque dado a cada qual e os momentos em que são trabalhados em aula são distintos, mas a análise das referências supracitadas permite afirmarmos que os problemas, os conceitos, as argumentações e os textos filosóficos são partes essenciais da Filosofia e, por conseguinte, da atividade filosófica em sala de aula.

Assim como são diversas as metodologias para o exercício do filosofar, inúmeras são as possibilidades de propostas de aula. A disciplina de Prática de Ensino de Filosofia IV tem como objetivo, pois, a elaboração e avaliação crítica de programas de ensino e planos de aula de Filosofia para o Ensino Médio. Nesse sentido, pode-se privilegiar uma das seguintes direções: a análise da Proposta Curricular do Estado de São Paulo (2008a) para a disciplina de Filosofia e, particularmente, os cadernos do Programa São Paulo Faz Escola (2008b), ${ }^{8}$ o exame dos livros didáticos de Filosofia contemplados no Programa Nacional do Livro Didático (PNLD), refletindo-se sobre as concepções de Filosofia e os recortes metodológicos que os embasam, a seleção temática, as atividades propostas e os textos filosóficos que os compõem; a elaboração, por parte dos alunos, de suas propostas filosófico-pedagógicas acompanhadas de seus respectivos planos de aula, condizentes com as condições de ensino previamente por eles assumidas.

Procura-se, dessarte, tanto mostrar que "a situação de ensinar Filosofia leva a ter de assumir algumas decisões teóricas” (CERLETTI, 2009, p. 12), de maneira a elucidar "o que se ensina em nome de esta Filosofia" (CERLETTI, 2009, p. 13), quanto tornar visível a apropriação teórica e sua transformação singular, por parte dos alunos, em cada proposta ou aposta de curso, nos diferentes planos de aula trabalhados na disciplina. Em outras palavras, procura-se, de um lado, refletir sobre as concepções de Filosofia implicadas nas propostas curriculares, nos livros didáticos examinados e/ou nas propostas formuladas pelos próprios alunos, bem como sobre os seus desdobramentos metodológicos intrínsecos. De outro lado, tudo isso é feito justamente com ou pelo recurso aos conteúdos filosóficos vistos nas disciplinas da Licenciatura, comuns ao Bacharelado, os quais são mobilizados nos planos de aula de maneira singular, a partir da proposta de curso feita por cada aluno. Convergem, portanto, nesse módulo de Prática de Ensino, os conteúdos vistos em outras disciplinas específicas da Licenciatura (Práticas de Ensino II, Políticas Educacionais, Filosofia do Ensino de Filosofia) e os de disciplinas não específicas. 
Na última prática de ensino do curso, a discussão sobre a Filosofia e suas interfaces no Ensino de Filosofia é aprofundada com a escolha de um tema ou uma área da Filosofia para ser trabalhado(a), tendo em vista suas possibilidades didáticas no nível médio de ensino. Todos os professores dos cursos de Filosofia (Licenciatura e Bacharelado) são convidados a pensar suas áreas de pesquisa no processo de formação voltado para o Ensino Médio, desenvolvendo atividades didáticas, planos de aula, análises de materiais didáticos específicos da área, textos filosóficos e de outros registros etc. Eventualmente, materiais didáticos e paradidáticos também podem ser criados no âmbito desta disciplina. Tal abertura, proporcionada por esta Prática de Ensino $\mathrm{V}$, além de permitir a imersão crítica e criativa em um tema/área visando o Ensino Médio, possibilita maior interação entre os docentes e discentes, e mantém um canal sempre livre para todos os docentes que, mesmo não tendo experiências prévias com o ensino (teóricas ou práticas), queiram participar desse processo que não se faz sem ressonâncias nas suas próprias atividades acadêmicas.

\section{Considerações finais}

As notas, aqui apresentadas, são fruto de uma reflexão quanto ao que impulsiona a Licenciatura em Filosofia da UFABC, constituída a partir de uma compreensão mais recente sobre o Ensino de Filosofia, cujos estudiosos (docentes e pesquisadores que se dedicam ao tema) são, felizmente, cada vez mais numerosos.

Vale destacar agora alguns elementos que fizeram parte do que foi exposto, retomando o objetivo do curso e seus desdobramentos na compreensão de prática aqui apresentada. O ponto de confluência das diferentes entradas que as práticas proporcionam ao curso em questão tem como origem (e finalidade) o que lemos inicialmente no Projeto Pedagógico do mesmo, a saber: a asseveração de uma formação que concilie "as reflexões sobre o ensino de Filosofia com as problematizações que caracterizam o filosofar". Isto faz com que o Ensino de Filosofia seja tomado, desde a base, como problema filosófico, e que o seu ensino (ou "ensino de seu ensino", ou a problematização do mesmo) requeira a articulação interna entre a prática docente e os conteúdos filosóficos - a intrínseca relação entre o "que" e o "como" se ensina. Fazer isso também requer uma nova postura por parte de alunos e professores, incipiente por ora, mas bastante alvissareira.

Partir da problematização sobre as possíveis justificativas para o ensino da Filosofia e o papel formativo desta no processo educacional (Prática I), pelo exercício de atribuição de sentido às coisas, de maneira que o homem atinja sua condição verdadeiramente humana, exige uma alteração subjetiva em relação ao conhecimento e à aprendizagem. Alteração que tem como efeito a transformação das relações estabelecidas entre o sujeito que participa da apropriação do saber e o mundo - autoaprendizagem e conscientização como personagem social. Tal processo de emancipação requer investigação sobre o que a legislação vigente atesta quanto aos conteúdos e metodologias para o ensino de Filosofia em nossa sociedade (Prática II), interpelando-a e problematizando, novamente, o domínio do ensino-aprendizagem. 
Faz-se necessário, também, o ensaio de distintas metodologias, experimentadas na prática (Prática III), com suas diferenças fecundas, mas preservando o que se considera fundamental no curso, que o ensino filosófico da Filosofia não se sustenta sem o filosofar, e que, como tal, constitui-se a partir de determinados elementos: problemas, conceitos, argumentação e investigação textual. Aprofundando e exercitando as possibilidades práticas do ensino é que se faz tanto a investigação das concepções de Filosofia presentes na legislação quanto a construção de propostas filosófico-pedagógicas por parte dos alunos (Prática IV). E, finalmente, é no mesmo sentido que se busca, pela escolha de um tema ou de uma área da Filosofia, aprofundar a discussão sobre a Filosofia e suas interfaces no Ensino de Filosofia (Prática V).

Ainda que expostas de maneira sequencial, todas as disciplinas abordadas constituem dimensões práticas que têm sua autonomia (não há pré-requisito para cursar qualquer uma delas), ao mesmo tempo em que dialogam umas com as outras, assim como com as demais disciplinas da Licenciatura, específicas ou comuns ao Bacharelado.

Por fim, todas essas dimensões da "prática" constituem um campo de experiência, cuja consequência (o que se espera durante e ao final do processo) não é apenas uma boa formação do aluno em conteúdos filosóficos, como o que talvez se espere de um bacharel, mas também a sua capacidade filosófica de pensar a própria prática de transmissão dos conteúdos filosóficos e o movimento (reflexão) que lhes é inerente fomentando pela prática docente novas experiências do pensamento.

\section{Referências}

ARENDT, H. A crise na educação. In: Entre o passado e o futuro. Tradução de ALMEIDA, M. B. de. São Paulo: Perspectiva, 2006, p. 221-247.

BRASIL. Ministério da Educação. Secretaria de Educação Básica. Orientações Curriculares para o Ensino Médio - Ciências Humanas e suas Tecnologias (vol. 3). Brasília: 2006.

BRASIL. Ministério da Educação. Secretaria de Educação Média e Tecnológica. Parâmetros Curriculares Nacionais para o Ensino Médio - Bases Legais. Brasília: 2000a.

. Parâmetros Curriculares Nacionais para o Ensino Médio - Ciências Humanas e suas Tecnologias. Brasília, DF, 2000b.

. Orientações Educacionais Complementares aos Parâmetros Curriculares Nacionais - Ciências Humanas e suas Tecnologias. Brasília: 2002.

BRASIL. Conselho Nacional de Educação. Parecer CNE/CP 9/2001. Diretrizes Curriculares Nacionais para a Formação de Professores da Educação Básica, em nível superior, curso de licenciatura, de graduação plena. Despacho do Ministro em 17/01/2002, publicado no Diário Oficial da União de 18/01/2002, Seção 1, p. 31. Brasília, DF, 2001.

CARRILHO, M. M. Razão e transmissão da filosofia. Lisboa: Imprensa Nacional-Casa da Moeda, 1987.

CÉSAR, M. R. de A.; DUARTE, A. ARENDT, H.: pensar a crise da educação no mundo contemporâneo. Educação e Pesquisa, São Paulo, v. 36, n. 3, p. 823-837, set./dez. 2010.

CEPPAS, F. Desencontros entre ensinar e aprender filosofia. Revista Sul-Americana de Filosofia e Educação, Brasília, n. 15, p. 44-54, nov.2010/abr.2011. 
CERLETTI, A. O ensino de filosofia como problema filosófico. Tradução de XAVIER, I. M. Belo Horizonte: Autêntica, 2009.

DELEUZE, G. Proust e os signos. Tradução PIQUET, A. e MACHADO, R. Rio de Janeiro: Forense Universitária, 2003.

.Diferença e Repetição. Tradução de ORLANDI, L. e MACHADO, R. Rio de Janeiro: Graal, 2006.

GALLO, S. Metodologia do ensino de filosofia: uma didática para o ensino médio. Campinas, SP: Papirus, 2012.

GELAMO, R. P. O ensino de filosofia no Brasil: um breve olhar sobre algumas das principais tendências no debate entre os anos de 1934 a 2008. Educação e Filosofia, Uberlândia, v. 24, n. 48, p. 331-350, jul./dez. 2010.

GOMES, G. S. R.; VELASCO, P. D. N. Por uma iniciação filosófica de crianças e jovens. In: CILENTO, A. Z.; INOCÊNCIO, D.; MASSON, T. J. (Org.). Licenciaturas em debate: ciência, ensino e aprendizagem, vol. 2. São Paulo: Plêiade, 2009, p. 395-402.

KOHAN, W. O.; OLARIETA, B. F. ; WOZNIAK, J. Repensando, com outras vozes, os sentidos do filosofar. In: KOHAN, W. O.; OLARIETA, B. F. A escola pública aposta no pensamento. (Org.). Belo Horizonte: Autêntica, 2012, p. 169-239. - (Coleção Ensino de Filosofia, 4).

LORIERI, M. A. Filosofia: fundamentos e métodos. São Paulo: Cortez, 2002. - (Coleção Docência em Formação)

OBIOLS, G. Sobre um modelo geral formal para o ensino de filosofia. In: OBIOLS, G. Uma introdução ao ensino da filosofia. Tradução de GALLO, S. Ijuí: Editora Unijuí, 2002, p. $103-$ 133.

RANCIÈRE, J. O mestre ignorante: Cinco lições sobre a emancipação intelectual. Tradução de DO VALLE, L. Belo Horizonte: Autêntica, 2002.

RUFFALDI, E. O ensino de Filosofia na Itália. In: GALLO, S.; CORNELLI, G.; DANELON, M. (Org.). Filosofia do Ensino de Filosofia. Petrópolis, RJ: Vozes, 2003, p. 134-150.

SÃO PAULO (Estado). Secretaria da Educação do Estado de São Paulo (SEE). Proposta Curricular do Estado de São Paulo: Filosofia, Ensino Médio. Coordenação Geral: Maria Inês Fini. São Paulo, SP, 2008a.

SÃO PAULO (Estado). Secretaria da Educação do Estado de São Paulo (SEE). Caderno do Professor: Filosofia, Ensino Médio. Coordenação Geral: Maria Inês Fini. São Paulo, SP, 2008b.

SEVERINO, A. J. A filosofia na formação do jovem e a ressignificação de sua experiência existencial. In: KOHAN, W. (Org.). Ensino de Filosofia: perspectivas. Belo Horizonte: Autêntica Editora, 2005, p. 183-194.

SILVA, F. L. História da Filosofia: centro ou referencial? In: NETO, H. N. (Org.). O ensino da filosofia no $2^{\circ}$ grau. São Paulo: SEAF/Sofia, 1987, p. 153-162.

. Por que filosofia no segundo grau. Estudos Avançados, 6 (14), 1992, p. 163-164.

TASSIN, E. La valeurformatrice de la philosophie. In: TASSIN, E. La grève des philosophes. Paris: Osires, 1986.

TOMAZETTI, E. M. Formação e Arte de viver: o que se ensina quando se ensina Filosofia?. In: PAGNI, P. A.; BUENO, S. F.; GELAMO, R. P. (Org.). Biopolítica, arte de viver e educação. Marília: Oficina Universitária; São Paulo: Cultura Acadêmica, 2012, p. 229-247.

UNIVERSIDADE FEDERAL DO ABC. Pró-Reitoria de Graduação. Projeto Pedagógico do Curso de Licenciatura em Filosofia. Santo André, 2010, 144p. 
VELASCO, P. D. N. Docência e Formação em Filosofia: para pensar o tempo presente. In: O que é isto, a Filosofia [na escola]?.1ª ed. São Paulo: Editora Laços - Selo Képos, 2014, p. 11-31.

\section{Notas}

${ }^{1}$ Não cabe no escopo deste trabalho discutir a noção de transmissão, nem tampouco a de disciplina escolar. Tomou-se esta última em seu sentido mais amplo, como conteúdo curricular. Sobre os diferentes sentidos do termo "transmissão", o leitor pode recorrer a Ceppas (2011); para uma discussão mais específica e aprofundada sobre a transmissão da Filosofia, sugere-se a leitura de Carillho (1987).

${ }^{2}$ As Orientações Curriculares para o Ensino Médio (2006) oferecem uma lista tão ampla quanto extensa que "tem por referência os temas trabalhados no currículo mínimo dos cursos de graduação em Filosofia e cobrados como itens de avaliação dos [...] professores de Filosofia para o ensino médio" (BRASIL, 2006, p. 34). Já as Orientações Educacionais Complementares aos Parâmetros Curriculares Nacionais apresentam eixos temáticos em que são listados temas e subtemas, de acordo com os "conceitos estruturadores e as competências sugeridas para a área em geral e para cada disciplina que a compõe em particular” (BRASIL, 2002, p. 52). Qual o modelo mais interessante para indicar caminhos curriculares?

${ }^{3}$ São elas: (i) ARANHA, M. L.; MARTINS, M. H. P. Filosofando: Introdução à Filosofia. 5a Edição. São Paulo: Moderna, 2013; (ii) CHAUÍ, M. Iniciação à filosofia. 2a Edição. São Paulo: Ática, 2013; (iii) COTRIM, G; FERNANDES, M. Fundamentos de Filosofia. 2a Edição. São Paulo: Saraiva, 2013; (iv) GALLO, S. Filosofia: experiência do pensamento.1 ${ }^{a}$ Edição. São Paulo: Scipione, 2013; (v) MEIER, C. Filosofia: por uma inteligência da complexidade. 2a edição. Belo Horizonte: Pax Editora, 2013.

${ }^{4}$ Estas são as disciplinas vigentes até o ano letivo de 2014.

${ }^{5}$ A disciplina Filosofia da Educação, cuja ementa é "A filosofia no processo de formação do homem. A Paidéia grega. O paradigma humanista-romântico. Formação e emancipação.” (UFABC, 2010, p. 76), não tem o viés de prática na concepção aqui discutida e, portanto, não está incluída nas referidas reflexões.

${ }^{6}$ Sobre o assunto, cf. Gelamo, 2010; Tomazetti, 2012; Velasco, 2014.

${ }^{7}$ Segundo Lorieri (2002, p. 51), "temáticas que se apresentam na forma de certas perguntas e para as quais há diversas respostas, algumas das quais presentes com mais força no cultural de cada época histórica”. E ainda: "questões que nós nos colocamos que pedem algo mais que constatações, descrições, explanações, quantificações, causas próximas. Elas nos pedem posicionamentos amplos e, ao mesmo tempo, significativos, de tal forma que nos ofereçam sentidos, quer como grandes explicações, quer como rumos de vida ou direções. Podemos chamar esses posicionamentos de referências, de princípios, de significações" (LORIERI apud KOHAN; OLARIETA; WOZNIAK, 2012, p. 214).

${ }^{8}$ A Secretaria do Estado de São Paulo distribui, aos professores e alunos da rede pública de ensino, cadernos organizados por bimestre, série e matéria, indicando o conteúdo a ser ministrado e oferecendo situações de aprendizagem. 
* Professora Doutora da Universidade Federal do ABC, São Bernardo do Campo, São Paulo, Brasil.

** Professora Doutora da Universidade Federal do ABC, São Bernardo do Campo, São Paulo, Brasil.

\section{Correspondência}

Marinê de Souza Pereira - Universidade Federal do ABC, Centro de Ciências Naturais e Humanas. Rua Arcturus (Jd Antares), Anchieta, CEP: 09606070 - São Bernardo do Campo, São Paulo, Brasil.

E-mail: marine.pereira@afabc.edu.br - patricia.velasco@ufabc.edu.br

Recebido em 23 de outubro de 2014

Aprovado em 11 de novembro de 2014 
